Volume 11, Issue 12, December 2020, pp. 736-756. Article ID: IJM_11_12_068

Available online at http://iaeme.com/Home/issue/IJM?Volume $=11 \&$ Issue $=12$

Journal Impact Factor (2020): 10.1471 (Calculated by GISI) www.jifactor.com

ISSN Print: 0976-6502 and ISSN Online: 0976-6510

DOI: 10.34218/IJM.11.12.2020.068

\title{
AN EMPIRICAL STUDY ON ANALYZING CUSTOMER BUYING BEHAVIOR TOWARDS JCB BACKHOE LOADER MACHINE AT DECCAN SALES AND SERVICES PRIVATE LIMITED, INDORE
}

\author{
Dr. Niraj Chimote \\ Associate Professor, IBS Hyderabad, India \\ Nadeem Islam Patel \\ Student of MBA Batch-2019-2021, IBS Hyderabad, India
}

\begin{abstract}
This study has been successfully conducted at Deccan Sales \& Services Private Limited, Indore, Madhya Pradesh. Deccan Sales \& Services Private Limited is an authorized distributor of Mahindra's Earth-Master backhoe loader, a mechanical excavator equipment. It draws itself a bucket attached to a hinged boom. The title of the study is, "An empirical study on analysing customer buying behaviour towards JCB backhoe loader machine at Deccan Sales \& Service Private Limited”. This study is a competitor study which is based on the hypothetical market structure, a concept of competitive strategies in Marketing Management. The aim of the study is to analyse the behaviour of customers of JCB backhoe loader and to identify the factors that are considered to be significant by the customer while making the purchase decision. A relevant literature on customer behaviour related to construction equipment has been reviewed and the research gaps have been explored accordingly. The gap analysis indicated that there is a need to explore factors that influence the purchase decision of the customer while purchasing backhoe loader machine. The objective of the project has been framed to explore the factors of brand selection of JCB backhoe loader machine and check which of these explored factors are significant in determining the purchase decision of JCB Backhoe loader machine. The variables are categorised as dependent and independent variables. The factors that influence purchase decision are independent variables (Brand name, Reliability, Service support, Past experiences, Recommendation, Resale value, Productivity, Fuel consumption, Operator comfort, Less downtime Parts network) and the number of sub decisions about purchasing backhoe loader machine are considered to be dependent variables (seller and location of a store, price of the product, Warrantee of the product, payment method like credit arrangements and maintenance arrangements). Based on
\end{abstract}


these variables identified in the literature review, a questionnaire was made for primary data collection. A 5 Point Likert Scale has been used to record the responses of the customers. The questionnaire has been administered to JCB backhoe loader customer in Indore region only. A simple random sampling method was used to categorized the responses from the entire population of JCB backhoe loader customers in Madhya Pradesh region, India. According to the sample size calculation obtained through a pilot study of first 90 responses, this survey has been conducted a total of 325 respondents (owners of JCB backhoe loader machine). The research methodologies that were adopted to accomplish the objective was exploratory factor analysis and multiple regression. A statistical tool namely SPSS was used to do the required computation and calculations. The analysis of data revealed through Varimax rotated component matrix that the three factors explored are basic requirements of the machine, brand image and productivity \& spare parts availability respectively. All these three factors have also been found to be significant in determining the purchase decision through multiple regression. However, their strength of association is found out 53.5\%, which could be improved by a few additional variables.

Key words: Backhoe Loader, Buying Process, Consumer Buying Behavior.

Cite this Article: Niraj Chimote and Nadeem Islam Patel, An Empirical Study on Analyzing Customer Buying Behavior towards JCB Backhoe Loader Machine at Deccan Sales and Services Private Limited, Indore, International Journal of Management, 11(12), 2020, pp 736-756.

http://iaeme.com/Home/issue/IJM?Volume=11\&Issue=12

\section{INTRODUCTION}

\subsection{Background of the Company}

The company was established in the year 1996 and was as "Deccan Sales \& Services Private Limited". It is an authorized distributor of various known brands like Cummins, Mahindra Construction Equipment, Wipro, Voltas, Bosch, L \& T, Fleet-guard, etc. Initially it was started with an authorized dealership of Cummins, India in 1996 and further expanded its business by acquiring dealership in other segments in the subsequent years. Today the company is instrumental in wholesaling and trading a wide range of best quality products like Brake Shoes, Construction Equipment, Disc Assembly, Oil Cooler, Recon Engine, Power Battery, Air Compressors and many more. Brake shoes, Disc Assembly and Oil cooler are highly demanded products and they are manufactured in streamlined manner, due to company's modern and upgraded infrastructural facility. The company has it's Headquarter located in Indore, Madhya Pradesh and offices in other states like Gujrat and Rajasthan.

\subsubsection{Mahindra's Construction Equipment}

The entire project is related to Mahindra Earth-Master Backhoe Loader Machine of Mahindra Construction Equipment. Mahindra's Construction Equipment is a brand under the global federation of companies "The Mahindra Group" worth 17.8 billion\$. The company has its major operations in countries like India, Bahrain, Bangladesh, Bhutan, Nepal, Sri Lanka and Tunisia. Mahindra's Construction Equipment offers various models of Mahindra's EarthMaster backhoe loader such as Mahindra Earth-Master VX, Mahindra Earth-Master S, Mahindra Earth-Master SX 90 2WD, Mahindra Earth-Master SX 90 4WD, Mahindra EarthMaster SXL and Mahinda Earth- Master SX 4WD. The company competitors include JCB backhoe loader, Caterpillar backhoe loader, Terex backhoe loader, Bull backhoe loader, CASE 
backhoe loader, Escort backhoe loader, Volvo backhoe loader, Komatsu backhoe loader and ACE backhoe loader.

\subsubsection{Concept of Consumer Behaviour (Kotler, 2015)}

Consumer behaviour is the study of people making decisions about what they buy, what they want, what they need, or how they act with respect to products and services including consumer's emotional, mental and behavioural responses. Consumer behaviour incorporates ideas from several sciences including Psychology, Biology, Chemistry and Economics. The consumer identity, his/her beliefs, specific needs, attitude and type of product available in the product category influence his/her buying behaviour. The success and failure of an organization is partially dependent on the degree of understanding the consumer behaviour. In modern times, the study of consumer behaviour in a right manner is a highly challenging task for marketer. Hence, understanding the buying behaviour in a correct manner helps a marketer to align appropriate company's strategies. By understanding the consumer behaviour in depth, a marketer predicts the future events and prepares himself/herself for future actions.

\subsubsection{Factors Influencing Consumer Buying Behaviour (Kotler, 2015)}

\section{Cultural factors}

The cultural factors that influence consumer buying behaviour are categorized as culture, sub culture and social class of the buyer.

\section{Culture}

A set of characteristics and knowledge of a particular group of people, their language, religion, cuisine, social habits, music, arts etc. is known as culture.

\section{Subculture}

It is a culture followed by a group of people within the culture that differentiates itself from the parent culture and these groups have similar habits, behavioural pattern and value system on the basis of their common experiences or location.

\section{Social Class}

It refers to the division of society on the basis of economic and social status. People, who belong to same social class, usually have similar status related to wealth, income and education.

Social class can be divided into four categories:

\section{Upper Class}

This is the class of rich people in the society who run a large business with high wealth status.

\section{Upper Middle Class}

It is the social group constituted by higher status of the middle-class group. It is completely contrast to the lower middle class.

\section{Middle Class}

This is the class of people in the society with moderate wealth status and income.

\section{Lower Class}

It is a social group with very less income and wealth status. 
An Empirical Study on Analyzing Customer Buying Behavior towards JCB Backhoe Loader Machine at Deccan Sales and Services Private Limited, Indore

\section{Social Factors}

Consumer buying behaviour of an individual is also influenced by family, colleagues at work, friends etc. A prospective customer analyses each aspect of the product or service before making a purchase decision with an intention to gather complete information of the product or service.

Social factors are categorised as mentioned below:

\section{Reference Group}

An individual's Attitude, values and behaviour are influenced by different group of people. This groups are known as reference groups.

\section{Family}

A group of people is related to each other by blood, marriage, adoption and reside with each other. This group of people is known as family.

\section{Personal Factors}

The different personal factors are as follows:

\section{Age \& lifecycle stage}

Couples marrying late in life, Childless couple, single parents etc. come under age \& life style stage.

\section{Occupation \& financial status}

Consumer behaviour is also influenced by the type of occupation and income level of an individual because they justify the financial status of an individual.

\section{Psychological factors}

Consumer behavior of an individual is also influenced by Psychological factors such as motivation, perception, beliefs, attitude and learning.

\subsubsection{Buying Decision Process (Kotler, 2015)}

The five stages of Buying Decision Process are:

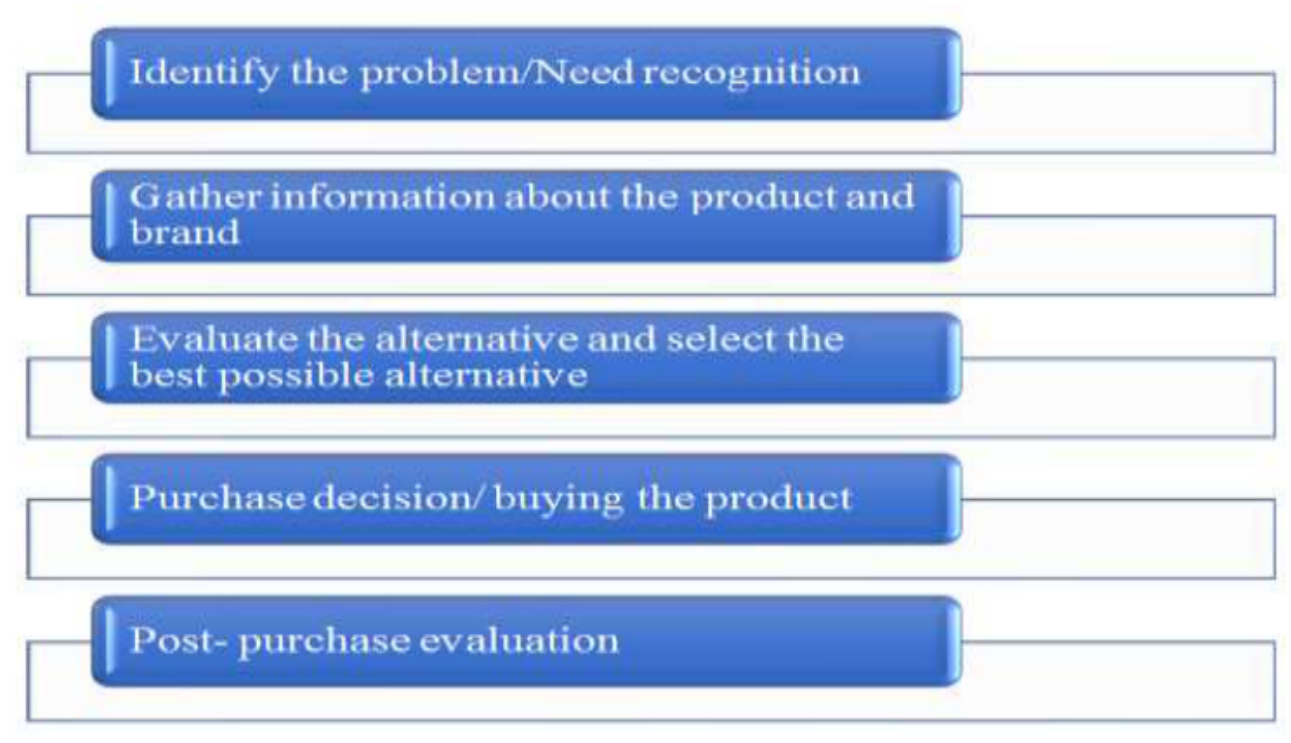

Figure 1 Buying Decision Process (Kotler, 2015) 


\section{Problem Recognition}

The buying decision process starts when a person recognises his/her need for the product or service. When the need occurs, it creates a urge inside the person and pushes him/her towards a product or service.

\section{Information Search}

When the need of an individual is identified and he/she starts gathering more information about the product or service it is called as information search.

\section{Evaluation of alternatives}

In this stage, different options related to the products or service are analysed by the consumer and he/she compares various alternative options before arriving at a particular choice.

\section{Purchase decision}

In this stage an individual's purchase decision depends on a number of sub-decisions like seller and location of a store, time of purchase, Size of the product, colour of the product, attractiveness of the package, delivery, warrantee, payment methods like credit arrangements, installation and maintenance arrangements.

\section{Post purchase behavior}

This is the last stage of buying decision process which in a consumer evaluates the performance of the product bought. The consumer is either satisfied or dissatisfied at this stage and he/she decides whether to go with the same product next time or not.

\subsubsection{Need of this study}

This study is conducted to identify the factors that customer would like to considers before purchasing JCB backhoe loader machine. Mahindra's Earth-Master is less expensive and provides ample of effective features with 4.5 LTR/HR of mileage but still customers may likely to go with JCB backhoe loader. JCB backhoe loader has gained years of trust in Indian backhoe loader market. However, the manner in which the company has positioned itself to this level is still not clear. As Deccan Sales \& Services Private Limited is an authorized distributor of Mahindra construction Equipment that deals with Mahindra's Earth-Master backhoe loader, the company wishes to overtake JCB backhoe loader's share in the backhoe loader market of Madhya Pradesh, India. This study will provide a path to Deccan Sales \& Services Private Limited by identifying all those factors which contributes the most and helps the company to make effective decisions with respect to Mahindra's Earth-Master backhoe loader. The expected outcome of this project may help Deccan Sales \& Services Private Limited to design consumer behaviour strategies to capture the market. Deccan Sales \& Services Private Limited has a great sales force team to contribute enormous to increase sales in construction equipment segment. This project will focus on developing a customer behaviour model for Deccan Sales \& Services Private Limited by highlighting the significant factors influencing customer behaviour towards JCB backhoe loader machine.

\subsubsection{Hypothetical Market Structure (Kotler, 2015)}

The study considered JCB brand specifically because it has the highest market share in the backhoe loader market of India. Therefore, it considered JCB Backhoe Loader as a market leader and Mahindra Earth-Master Backhoe Loader as a market challenger. The concept of Hypothetical Market Structure states that a market challenger can become a market leader, if it adopts all the useful steps that are followed by a market leader. 


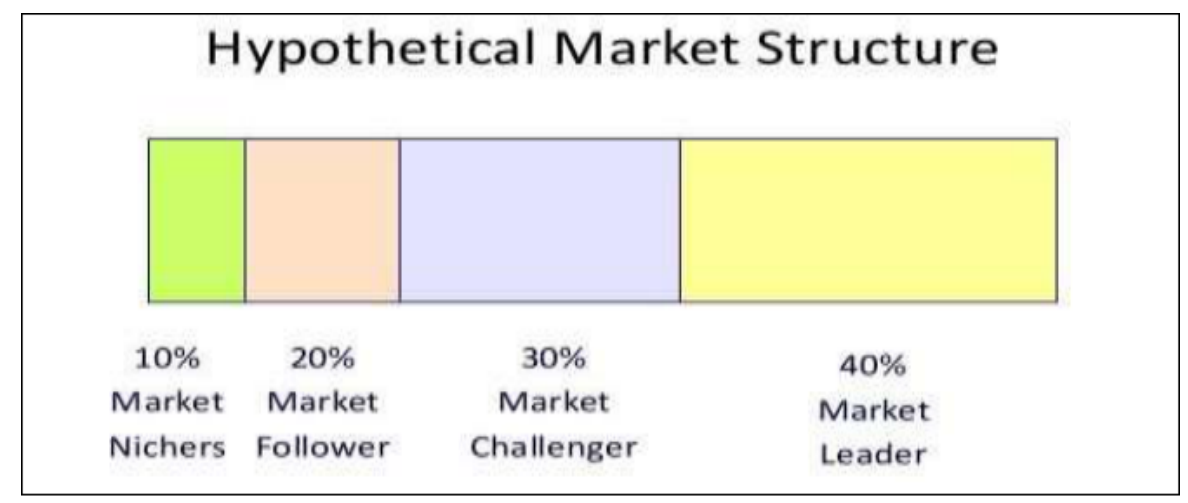

Figure 2 Hypothetical Market Structure (Kotler, 2015)

\section{LITERATURE REVIEW}

The Literature Review aims to explore, the important variables related to backhoe loader machine that may impact purchase decision of the customers.

The articles reviewed reveal some of the critical dimension of the backhoe loader machine.

\subsection{Dynamics of Industrial Buyer Behaviour of Loader Backhoe (Panchantham et.al., 2014)}

This study has been conducted to investigate the buying behaviour of business component of marketing. The major emphasis was on industrial marketing of construction equipment namely backhoe loader machine. Its objective was understanding the buyer's behaviour towards backhoe loader machine among Indian customers. It considered various backhoe loader brands such as JCB, L\&T, Telcon, CAT, Terex, Escorts and others. Variables such as brand awareness, past experience, Reliability, Resale value, Productivity, Service parts and network and less downtime were considered. The sample was selected on the basis of nonrandom purposive sampling method. Primary data was collected from 387 buyers of backhoe loader across India with the help of self-administered questionnaires. The hypotheses were formulated and tested with the help of business analytics tools such as chi-square, regression and ANOVA. Chi-square was tested on brand awareness factors such as location of the industry, type of industry, reasons for switching, years in profession, types of Equipment owned, length of Profession, age of Respondents and qualifications. It was found that brand awareness was associated with the factors such as location of the industry, Years in profession, types of equipment owned, age and qualifications of the respondents. Regression Analysis was conducted on variables of brand selection and it was found that attributes such as Resale value, Productivity, Service parts and network and less downtime has significantly influenced the brand selection. With regard to the product quality the satisfaction level on Machine delivery as per commitment and Machine performance were found to be high by the customer of L\&T. The satisfaction level on no major issues at the time of consuming and machine performance was found to be high by the customers of JCB. The customers were satisfied with the product reliability of L\&T Case and JCB. Brands such as CAT and Telcon are followed by L\&T Case and JCB in that sequential order with respect to satisfaction of product reliability. Brands such as Escorts and Terex stand last in sequence on respondents' satisfaction with regards to product reliability. It was concluded that the brand selection by the buyers of backhoe loader was influenced by brand awareness, past experience, Reliability, Resale value, Productivity, Service parts and network and less downtime. It was found that 
JCB had a high market share and L\&T Case to be the next competitor for JCB in the entire backhoe loader segment.

\subsection{The following are the gaps identified in this study:}

Research Gap 1: Warrantee and price have been considered as variables of brand selection however warrantee and price must be considered as variables that influence the purchase decision of a backhoe loader machine because both the variables are proved as a part of sub decisions that altogether defines purchase decision.

Research Gap 2: One of the variables considered determining product quality with respect to brand given is machine delivery as per commitment. However, this variable must not be considered as a variable of product quality because product quality means, "Incorporating the features that have a capacity to meet customer needs, wants and give customer satisfaction by improving products and making them free from any deficiencies and defects". However, the delivery of a backhoe loader as per commitment is not a feature of a backhoe loader and hence it does not make any difference in the quality of a backhoe loader.

Research Gap 3: The variable considered for determining product reliability with respect to brand given in the article is Aesthetics of the new machine However, it must not be considered as a variable of product reliability because reliability means performing consistently or the quality of being trustworthy while on the other side aesthetics of a new machine deal with beauty of a new machine mainly. Hence, reliability cannot be measured accurately through this variable.

\subsection{Quantifying the Factors Influencing Buyer's Purchase Decision in the Light Commercial Vehicle: A Study Conducted in the Pune Region (Sengar, 2019)}

This study has been conducted to determine the customer preference while buying Light commercial Vehicle. The objectives of the study were to identify the factors which influenced customer decision making process of Light Commercial Vehicles and to study the significance between demographic variables and different attributes of Light Commercial Vehicles. It considered various attributes such as Mileage, Performance, Serviceability, Availability of spare parts, Technology and Down payment to identify the ones that are contributing to the increase in sales of the vehicles. Primary data has been collected from active users as well as customers with the help of self-administered questionnaire. Simple Random Sampling has been used. 355 Buyers and Users of Light Commercial Vehicles in the Pune region were included for this study. Business analytics tools such as Correlation, Factor and regression analysis were used with the help of SPSS Software. Correlation analysis was conducted on the attributes to identify a positive correlation among them. Factor analysis was conducted to explore the variables that customers preferred with respect to light commercial vehicles and group them into factors. Regression analysis was conducted to identify the relationship between the significant factors. The major finding of the proposed study was that factors such as availability of spare parts, loading capacity, down payment and brand, mileage of the vehicle, after sales service were the most significant contributors to the buyers at the time of purchase.

\subsection{The following are the gaps identified in this study}

Research Gap 1: In this study, attributes such as Mileage, Performance, Serviceability, Availability of spare parts, Technology and Down payment are mentioned as attributes that accolade and hike the sales of the vehicles. These attributes must be considered as attributes that contribute towards increase in sales because customer decision making process is also influenced by other major factors like price and maintenance cost. 
Research Gap 2: One objective of the study is dependent upon consumer behaviour concept so it is highly required to mention consumer behaviour theory before literature review.

Research Gap 3: Questionnaire must be mentioned in the study.

Research Gap 4: It should be Convenience sampling instead of simple random sampling method.

\subsection{A study and analysis of construction equipment management used in construction projects for improving productivity (Manikandan et.al., 2018)}

Construction business is dependent upon industrial products like backhoe loader, Excavators, Dragline excavators, Bulldozers, Graders, Wheel tractor scrappers and many more. The study indicates the benefits of implementing total Productivity while purchasing, leasing or renting the equipment, and guide in optimizing the profitability. Different methods of life cycle cost estimation and decision methods were researched and compared. The study considered variables such as Improper cash flow, Improper Training, Preventive maintenance, Cost overrun, Unplanned budget, Delay analysis, Resale value, Poor supervision, Un-routine maintenance and Owning cost. The objective of the study was to enhance the equipment effectiveness in a construction company. It used both primary and secondary data for analysis. Primary data was collected with the help of self-administered questionnaire, interview, literature review and observation check list, whereas secondary data was generated through a review of relevant documents. Questionnaires were distributed for 15 construction companies in India. Purposive sampling technique was used to identify the sample size. Hypotheses was formulated and tested on some expected results. Factor Analysis was conducted with the help of SPSS software. The findings of this study were compared with findings of questionnaire conducted to identify significant commonalities and differences in equipment management practices. It was concluded that factors such as frequent equipment breakdowns, maintenance of equipment, insufficient number of equipment, performance and efficiency of equipment and inadequate modern equipment systems were the most significant factors that contributed in improving productivity of a construction business.

The following is the gap identified in this study

Research Gap: Information related to questionnaire is missing.

\section{Evaluation of Factors Affecting on Construction Equipment Acquisition Methods in Malaysia (Sajoudi et.al., 2011)}

The construction industry constitutes an important element of the Malaysian economy. This study focussed on construction companies in Malaysia, especially in Johor Bahru and Kuala Lumpur, to evaluate the financial and non-financial factors. The objective of the study was to evaluate the factors that affect construction equipment acquisition methods in Malaysia. It used both primary and secondary data for analysis. Secondary data sources were used to identify the financial factors affecting on construction equipment acquiring method whereas the primary data was collected through interviews. The interview was divided into two main stages which were preliminary interview and main interview. Initially preliminary interview was conducted through communicating with the key personnel of contractor companies. The interviews were conducted by asking open ended questions. T-test was conducted to evaluate the factors that affect construction equipment acquisition methods in Malaysia. It was concluded that the contractors should consider both financial and non-financial factor to make a good decision at the time of purchase of construction equipment. 
The following is the gap identified in this study:

Research Gap: Sampling size calculations is missing.

\section{A conceptual study on industrial buying behaviour on heavy commercial vehicle in India} (Sharma \& Sharma, 2017)

It is very important for new organization to make their strong brand image by adapting new technology which can give better mileage, Quality of the product, Life of the product and most importantly post-sale services. This study discussed the two Laws for customer loyalty and brand performance i.e. Double Jeopardy (DJ) and Duplication of purchase law (DoPL). In DJ, it was discussed about loyalty and penetration, which was connected with market share and purchase frequency. In DoPL, it was discussed about the switching of brand between bigger brands and smaller brands. In this research, various models were used to find out the compound annual growth rate (CAGR) of the brands and penetrations of the brands. The study considered secondary data for analysis. Total 97 articles were found for this research out of which 33 articles were reviewed for this study, based on those articles industrial buying behaviour, types and implementation process were studied and explained. The study considered various companies like Mahindra \& Mahindra, Eicher, Tata Motors, Ashok Leyland and Force. It was found that Tata Motors had the highest market share followed by Mahindra and Mahindra. The objective of the study was to understand the Industrial buying behaviour in heavy commercial vehicle in India. It was concluded that Industrial buying behaviour was not researched mostly among researchers. The Double Jeopardy Law stated that a bigger brand has more penetration as compared to the smaller brands. In the research findings customers were more loyal to the bigger brands as compare to the smaller brands. It was very difficult for the new entrants to sustain in the market and for sustainability they had to make their strong brand image by adapting latest technology which can give better mileage, Quality of the product and Life of the product.

The following is the gap identified in this study:

Research Gap: There is no quantitative evidence to prove the research results.

\section{Research Objectives}

To explore the factors of brand selection of JCB backhoe loader machine

To check which of the explored factors are significant in determining the purchase decision of JCB Backhoe Loader.

\section{Based on the Literature Review, the following are the research questions on which the objectives have been formulated}

What are the factors that influence the customer for brand selection of JCB backhoe loader machine?

While making purchase decision of a JCB backhoe loader machine what could be the most significant factors that affect their brand selection?

\section{RESEARCH METHODOLOGY}

The objectives of the study have been formulated on the basis of gaps identified in the literature review. This chapter describes the research methodology in a logical sequence which can be adopted to achieve these objectives. The components of research methodology (Kotler, 2005) are as follows: 


\subsection{Identifying and defining the problem}

It is the initial step in the research process where the objectives of the study are formulated. The research problems and objectives have been formulated. Accordingly; the research design is formulated as under.

\subsection{Methodology for the objective}

\section{Research Design (Malhotra \& Dash, 2009)}

A research design is the actual framework of a research that provides specific details regarding the process to be followed in conducting the research. It can be defined as the plan and structure of enquiry formulated in order to obtain answers to research questions. It is a framework or blueprint for conducting the research projects. It specifies the details of the procedures necessary for obtaining the information needed to structure and solve research problems.

\section{Type of Research Design Descriptive research}

It is used to describe characteristics of a population or phenomenon being studied. It does not answer questions about how/when/why the characteristics occurred.

It is very necessary to select an appropriate and specific research design before the actual research work is started. The present study is a descriptive research where the objectives are clearly established and details about all aspects of a problem situation (CBB) are gathered. Irrespective of the problem's complexity, it is necessary to design this conclusive research efficiently in such a manner that it should form the basis for an analytical study that would help in developing hypothesis.

\section{Specification of the measurement and scaling procedure}

The study consists of usage of Likert's scale for measuring the variables. So, the respondent needed to select a numerical score (like 1 or 2 or 3 or 4 or 5 ) for each statement to indicate the degree of agreement or otherwise. Each score has to be finally added up to measure the respondent's attitude. Thus, a Likert's scale can be used to measure them. This customer buying behaviour study required the prospective customer responses in the form of degree of agreement or disagreement to express their attitude towards purchasing JCB backhoe loader machine therefore an attitude measurement scale like Likert scale was chosen for the study.

\section{Survey}

It is a research technique which is used to gather information from a sample of respondents by employing a questionnaire to obtain primary data. It is the data which is gathered first hand to answer the research question being investigated. The present study involved personal interaction with the respondents (Customers) by asking them to fill the questionnaire. However, due to enforced Covid19 lockdown restrictions in India during this period, a traditional telephonic survey was conducted to collect the responses and the structed questionnaire was filled accordingly.

\section{Description of the Questionnaire}

The questionnaire has been prepared on the basis of dependent variables (Purchase decision factors of a JCB Backhoe Loader Machine) and independent variables (Brand selection Factors of a JCB Backhoe Loader Machine) identified in the Literature review. It is provided in the Appendix 1. 


\section{Purchase Decision (Dependent Variables)}

Seller and location of a store (Kotler, 2015)

Seller stands for a dealer that buys backhoe loader machines from the manufacturer and sell them directly to the end customers. Store location refers to a place where the showroom of the backhoe loader machines is situated.

\section{Price of the product (Kotler, 2015)}

It is the amount of money required or given to purchase a backhoe loader machine.

\section{Warranty of the product (Kotler, 2015)}

It refers to a written document that a customer receives from the company's dealer while purchasing a backhoe loader machine. This written document consists of promises with respect to repair or replace, if the backhoe loader machine is found to be defective or does not work.

\section{Payment method like credit arrangements (Kotler, 2015)}

Credit arrangements are the finance facilities that a dealer offers for its customers from respective banks in the form of loans or EMI's while purchasing a backhoe loader machine.

\section{Maintenance arrangements (Kotler, 2015)}

It refers to regular service arrangements, which are offered by the backhoe loader dealers to its respective customers in order to maintain the performance of the machine.

\section{Brand Selection Factors (Independent Variables)}

\section{Brand Name (Panchantham et.al., 2014)}

It refers to the name and internalised impression of a backhoe loader machine company through which the backhoe loaders are recognised and identified by the customers.

\section{Reliability (Panchantham et.al., 2014)}

It refers to the consistency of a backhoe loader machine in terms of its performance.

\section{Service Support (Panchantham et.al., 2014)}

Service support includes presence of competent service personnel, who are available at service for any kind of help or support required by the backhoe loader machine owner in relation to problems related to the machine performance and its effective functioning.

\section{Past Experience (Panchantham et.al., 2014)}

It refers to the prior knowledge of the functioning of the backhoe loader machine based on previous experience of its usage.

\section{Recommendation (Panchantham et.al., 2014)}

Recommendation means reference provided by backhoe loader machine owner to any other prospective customer, who has a plan to purchase backhoe loader machine anytime soon.

\section{Resale Value (Panchantham et.al., 2014)}

The value at which backhoe loader machine is sold by the owner at a reduced price after 1-5 years of usage (lesser than the original purchase price). 
An Empirical Study on Analyzing Customer Buying Behavior towards JCB Backhoe Loader Machine at Deccan Sales and Services Private Limited, Indore

\section{Productivity (Panchantham et.al., 2014)}

It refers to the output (Machine performance at work) of the backhoe loader machine with respect to the input (effective functioning of the machine).

\section{Fuel Consumption (Panchantham et.al., 2014)}

It refers to the mileage/hour that a backhoe loader machine provides at the time performance.

\section{Operator Comfort (Panchantham et.al., 2014)}

It refers to the availability of facilities (example Joystick, Air Conditioning etc.) required for the operator inside his cabin.

\section{Less Downtime (Panchantham et.al., 2014)}

It refers to the time for which the backhoe loader machine is idle.

Parts Network (Panchantham et.al., 2014)

Parts network refers to the availability of genuine spare parts easily.

\subsection{Selecting a Sampling procedure}

A process that uses a small number of items or a small portion out of a population to draw conclusions regarding the whole population is known as sampling. It can also be defined as the act, process or technique of selecting a representative part of a population for the purpose of determining the characteristics of the whole population. The following are the multiple stages of the sampling process:

\section{Stage I-Defining target population}

Target population is the collection of elements that possess the information sought by the researcher and about which inferences are to be made. The target population of this study includes all the JCB Backhoe Loader customers at Madhya Pradesh, India. The sampling unit are the respondents from whom the data was collected.

\section{Stage II-Specifying the sampling frame}

A sampling frame is a list of elements from which the sample may be drawn. In this case, the sampling frame is the list of JCB Backhoe loader customers from Indore and select cities of Madhya Pradesh, India.

\section{Stage III-Selecting a Sampling Technique}

The technique that was considered suitable for this study depending upon all the practical difficulties is the one in which an element cannot be included in the sample more than once i.e. sampling without replacement.

\section{Stage IV-Selecting the Customers}

The next step is to decide the target customer. A sampling process where each element in the target population has an equal probability of inclusion in the sample is known as Simple Random Sampling. The steps followed were as follows:

- The sampling frame was compiled consisting of the contact details of JCB Backhoe Loader customer in Indore and select cities of Madhya Pradesh, India. Each respondent in the sampling frame was assigned a unique identification number. 
- Then, random numbers were generated to determine which respondent to be included in the sample.

- A Telephonic Interview was conducted for each respondent that was included in the sample.

- The responses for the structured questionnaire were recorded through the telephonic interviews (Because of Covid19 Lockdown restrictions).

- Finally, the responses were analysed accordingly.

\section{Stage V-Determination of sample size}

The sample size plays a crucial role in the sampling process. In the case of a probability sampling; formulae are used to calculate sample size. There are three analyses in this study. Every analysis has different number of variables. However, it is essential to consider three factors while determining sample size for problems involving means. They are standard deviation of the population, the acceptable level of sampling error and the expected confidence level.

\subsection{Sample Size Calculations}

The mean Sample Standard Deviation was calculated on the basis of Pilot study Conducted in order to calculate the final sample size. The pilot study was conducted on first 90 respondents selected randomly because as rough guidelines for conducting factor analysis, there should be at least four or five times as many observation (sample size) as there are variables (Malhotra \& Dash,2009). The following table displays sample standard deviation for all the 90 responses collected for pilot study.

Table 1 Sample Standard Deviation- Customers of JCB Backhoe Loader Machine

\begin{tabular}{|l|c|l|c|c|}
\hline Type of variable & $\begin{array}{c}\text { S.N (As per } \\
\text { questionnaire) }\end{array}$ & \multicolumn{1}{|c|}{ Name of Variables } & $\begin{array}{c}\text { N } \\
\text { Statistic }\end{array}$ & $\begin{array}{c}\text { Std. Deviation } \\
\text { statistic }\end{array}$ \\
\hline Independent & 6 & Brand Name & 90 & 1.32092 \\
\hline Independent & 7 & Reliability & 90 & 1.0145 \\
\hline Independent & 8 & Service Support & 90 & 1.07989 \\
\hline Independent & $9(\mathrm{a})$ & Past Experience & 90 & 1.45 \\
\hline Independent & $9(\mathrm{~b})$ & Resale Value & 90 & 1.06053 \\
\hline Independent & $9(\mathrm{c})$ & Productivity & 90 & 0.50168 \\
\hline Independent & 10 & Recommendation & 90 & 0.84239 \\
\hline Independent & 11 & Fuel Consumption & 90 & 0.85715 \\
\hline Independent & 12 & Operator Comfort & 90 & 1.11084 \\
\hline Independent & 13 & Less Downtime & 90 & 1.01947 \\
\hline Independent & 14 & Service and parts network & 90 & 0.67124 \\
\hline Dependent & 1 & Seller and location of a & 90 & 1.09982 \\
& & store & & \\
\hline Dependent & 4 & Credit Arrangements & 90 & 0.49668 \\
\hline Dependent & 5 & Maintenance Arrangements & 90 & 0.56577 \\
\hline Dependent & 2 & Price of the Product & 90 & 0.90938 \\
\hline Dependent & 3 & Delivery and Warrantee & 90 & 0.69094 \\
\hline & & & & \\
\hline & & Mean Standard Deviation & & $\mathbf{0 . 9 1 8 2}$ \\
\hline
\end{tabular}


An Empirical Study on Analyzing Customer Buying Behavior towards JCB Backhoe Loader Machine at Deccan Sales and Services Private Limited, Indore

The standard formula for sample size is given as-

$\mathrm{n}=(\mathrm{ZS} / \mathrm{E})^{2}$

$Z=$ Standardized Value corresponding to a confidence level $(95 \%)=1.96$ (Normal Distribution Table)

$\mathrm{S}=$ Mean Sample standard deviation $=0.9182$ (From Table 1)

$\mathrm{E}=$ Acceptable level or Margin of error $=0.1$ (Approx.) (Malhotra \& Dash, 2009)

$\mathrm{Z}=1.96$

$\mathrm{S}=0.9182$

$\mathrm{E}=0.1$

$\mathrm{n}=(1.96 * 0.9182 / 0.1)^{2}$

$\mathrm{n}=(17.99672)^{2}$

$\mathrm{n}=323.881931$

\subsection{Questionnaire Survey}

A Questionnaire has been prepared on the basis of the information reviewed in the literature analysed. The questionnaire survey is based on factor influencing customer buying behaviour but related to brand selection (Independent Variables) and a few numbers of sub decisions about purchase of a JCB backhoe loader machine (Dependent Variables).

\section{ANALYSIS OF DATA}

The research methodology highlighted the various research methods used in the study. The various parameters, terminologies and variables defined in the research methodology had to be inspected, cleaned (making it error-free) and transformed to a suitable format. Thus, the analysis of data has been carried out with reference to the objectives of the study as defined in chapter II and research methodology to highlight useful information, suggest conclusion and support decision making. All the statistical tables have been given in sequential order in this chapter. However, final models of stepwise regression tables have been incorporated in this chapter and the complete stepwise regression tables have been given below. As a rough guideline, there should be at least four or five times as many observations (sample size) as there are variables (Malhotra \& Dash, 2009). Hence, the break-up of the minimum number of responses has been given in Table 2 as follows:

Table 2 Minimum responses required for Factor Analysis

\begin{tabular}{|l|c|c|}
\hline \multicolumn{1}{|c|}{ Analysis } & Number of metric variables & $\begin{array}{c}\text { Minimum number of responses } \\
\text { required (Number of } \\
\text { independent Variables*5) } \\
\text { (Malhotra \& } \\
\text { Dash,2009) }\end{array}$ \\
\hline $\begin{array}{l}\text { Purchase Decision of a JCB } \\
\text { Backhoe Loader Machine }\end{array}$ & 11 & 55 \\
\hline Total & 11 & 55 \\
\hline
\end{tabular}

\subsection{Reliability Analysis}

The survey questionnaire had to be tested for its reliability. An analysis was conducted for checking the reliability of the questionnaire and the results were obtained. The Cronbach's alpha (a measure of reliability) score has been calculated. The results have been summarized in Table 3 as mentioned below. 
Table 3 Cronbach's alpha score

\begin{tabular}{|c|c|}
\hline \multicolumn{2}{|c|}{ Reliability Statistics } \\
\hline Cronbach's Alpha & N of Items \\
\hline 0.853 & 16 \\
\hline
\end{tabular}

This coefficient varies from 0 to 1 , and a value of 0.6 less generally indicates unsatisfactory internal consistency reliability (Malhotra \& Dash, 2009). The Chronbach's alpha value $(0.853)$ indicates that there is internal consistency in the selected data.

\subsection{Customer Purchase Decision of a JCB Backhoe Loader Machine Objectives of the Project}

To explore the factors of brand selection of JCB backhoe loader machine.

To check which of the explored factors are significant in determining the purchase decision

\section{Exploratory Factor Analysis}

Step One: According to the questionnaire described in Chapter III, the following are the variables used in this analysis: Brand name, Reliability, Service support, Past experiences, Recommendation, Resale value, Productivity, Fuel consumption, Operator comfort, Less downtime and Service and parts network.

Step Two: Null Hypothesis: Variables are uncorrelated in the population (The population correlation matrix is an identity matrix). From Table 4, the Approx. Chi- Square value is 2034.868 and it has found to be significant at 0.05 level of significance which indicates that the null hypothesis can be rejected and it may be concluded that variables are correlated in the population. The chi-square statistic is used only for Bartlett's test of sphericity and its value will help in concluding whether the variables are correlated or not. The Kaiser-Meyer-Olkin (KMO) measure of Sampling Adequacy is found out to be 0.826 . High values (between 0.5 to 0.10 ) indicate factor analysis is appropriate. Values below 0.5 imply that factor analysis may not be appropriate.

Table $4 \mathrm{KMO}$ and Bartlett's Test

\begin{tabular}{|l|l|l|}
\hline \multicolumn{3}{|c|}{ KMO and Bartlett's Test } \\
\hline Kaiser-Meyer-Olkin Measure of Sampling Adequacy. & 0.826 \\
\hline \multirow{4}{*}{ Bartlett's Test of Sphericity } & Approx. Chi-Square & 2034.868 \\
\cline { 2 - 3 } & df & 55 \\
\cline { 2 - 3 } & Sig. & 0.000 \\
\hline
\end{tabular}

Step Three: The factor analysis has been conducted through a method called as PrincipalComponents method. In principal component analysis, the total variance in the data is considered. It is recommended when the primary concern is to determine the minimum number of factors that will account for maximum variance in the data for use in subsequent multivariate analysis (Malhotra \& Dash, 2009).

Step Four: Determine the number of factors: It is observed from Table 5, that the total variance explained is 70.700 . 
An Empirical Study on Analyzing Customer Buying Behavior towards JCB Backhoe Loader Machine at Deccan Sales and Services Private Limited, Indore

Table 5 Total Variance Explained

\begin{tabular}{|c|c|c|c|c|c|c|}
\hline \multirow{2}{*}{ Component } & \multicolumn{3}{|c|}{ Initial Eigenvalues } & \multicolumn{3}{c|}{ Extraction Sums of Squared Loadings } \\
\cline { 2 - 7 } & Total & \% of Variance & $\begin{array}{c}\text { Cumulative } \\
\text { \% }\end{array}$ & Total & \% of Variance & $\begin{array}{c}\text { Cumulative } \\
\text { \% }\end{array}$ \\
\hline & & & & & & \\
\hline 1 & 5.001 & 45.459 & 45.459 & 5.001 & 45.459 & 45.459 \\
\hline 2 & 1.795 & 16.319 & 61.778 & 1.795 & 16.319 & 61.778 \\
\hline 3 & 0.981 & 8.922 & 70.700 & 0.981 & 8.922 & 70.700 \\
\hline 4 & 0.784 & 7.130 & 77.830 & & & \\
\hline 5 & 0.629 & 5.717 & 83.548 & & & \\
\hline 6 & 0.600 & 5.456 & 89.004 & & & \\
\hline 7 & 0.347 & 3.155 & 92.158 & & & \\
\hline 8 & 0.306 & 2.781 & 94.940 & & & \\
\hline 9 & 0.223 & 2.023 & 96.963 & & & \\
\hline 10 & 0.176 & 1.603 & 98.566 & & & \\
\hline 11 & 0.158 & 1.434 & 100.000 & & & \\
\hline
\end{tabular}

Table 6 Varimax Rotated Component Matrix

\begin{tabular}{|l|c|c|c|}
\hline \multicolumn{1}{|c|}{ Name of the Variable } & \multicolumn{3}{|c|}{ Component } \\
\cline { 2 - 4 } & $\mathbf{1}$ & $\mathbf{2}$ & $\mathbf{3}$ \\
\hline Brand Name & 0.091 & 0.914 & -0.007 \\
\hline Reliability & 0.748 & 0.259 & 0.058 \\
\hline Service Support & 0.808 & -0.253 & 0.280 \\
\hline Past Experiences & 0.738 & -0.099 & 0.506 \\
\hline Resale value & 0.139 & 0.865 & 0.318 \\
\hline Productivity & 0.282 & 0.502 & 0.576 \\
\hline Recommendation & 0.771 & 0.412 & 0.099 \\
\hline Fuel Consumption & 0.634 & 0.104 & 0.476 \\
\hline Operator Comfort & 0.757 & 0.291 & 0.077 \\
\hline Less Downtime & 0.362 & 0.255 & 0.508 \\
\hline Parts Network & 0.055 & 0.057 & 0.793 \\
\hline
\end{tabular}

Because of prior knowledge gained through literature review, there was a expectation for the number of factors before- hand. Thus, the number of factors to be extracted have been specified in the SPSS computer program allowing for a simpler implementation of priory determination approach (Malhotra \& Dash, 2009).

Step Five: The Table 6 displays the Varimax rotation matrix. Varimax procedure has been used because it has minimised the number of variables with high loading on a factor thereby enhancing the interpretability of the factors.

Step Six: Interpretation of factors: The results of Varimax rotation are summarized as below:

Table 7 Summary Table of Factors

\begin{tabular}{|l|l|l|}
\hline $\begin{array}{c}\text { Factor 1- } \\
\text { Basic requirements of the machine }\end{array}$ & \multicolumn{1}{|c|}{ Factor 2- Brand Image } & $\begin{array}{c}\text { Factor 3- } \\
\text { Productivity and spare parts } \\
\text { availability }\end{array}$ \\
\hline Reliability & Brand Name & Productivity \\
\hline Service Support & Resale value & Less Downtime \\
\hline Past Experiences & & Parts Network \\
\hline Recommendation & & \\
\hline Fuel consumption & & \\
\hline Operator comfort & & \\
\hline
\end{tabular}


Factor 1: The following are the variables (Reliability, Service Support, Past Experience, Recommendation, Fuel Consumption and Operator Comfort) that have the highest loading on factor 1 after rotation.

The above factor has been newly named as Basic requirements of the machine as all the variables indicate the initial focus of the buyer while making a purchase decision of a JCB backhoe loader machine.

Factor 2: The following are the variables (Brand Name, Resale Value) that have the highest loading on factor 2 after rotation:

The above variables indicate an Image of the Brand done by company on marketing of JCB Backhoe Loader Machine. Thus, it is named as Brand Image.

Factor 3: The following are the variable (Productivity, Less Downtime and Parts network) that has the highest loading on factor 3 after rotation:

The above variables indicate productivity and spare parts availability as these variables contribute towards performance of the machine.

\subsection{Multiple Regression}

A multiple regression analysis was used to obtain the results. The results of the factor analysis $\left(F_{1}, F_{2}\right.$ and $\left.F_{3}\right)$ were carried forward for conducting multiple regression analysis in which the dependent variables were considered as Mean Purchase decision. The regression equation (Levin \& Rubin, 2002) is as follows: $Y=\alpha+\beta_{1} F_{1}+\beta_{2} F_{2}+\beta_{3} F_{3}$

Where $Y=$ Mean Purchase Decision (Mean of the four Marketing program variables namely Seller and location of a store, Price of the product, Delivery and warrantee, credit arrangements and maintenance arrangements respectively)

$\alpha=$ Intercept.

$\mathrm{F}_{1}=$ Basic requirement of the machine $\mathrm{F}_{2}=$ Brand Image

$F_{3}=$ Productivity and spare parts availability $\beta_{1}, \beta_{2}, \beta_{3}=$ Slopes associated with $F_{1}, F_{2}, F_{3}$ Inference about the Regression as a whole using an F-test

Null Hypothesis: Y does not depend upon the Fi's i.e. $H_{0}: \beta_{1}=\beta_{2}=\beta_{3}=\quad \beta_{k}=0$

Alternate Hypothesis: $Y$ depends on at least one of the Fi's i.e. $H_{1}$ : at least one $\beta_{i} \neq 0$

Tables 8, 9 and 10 are based on model 3 which has emerged out as an acceptable model in the Stepwise Regression Analysis. The tables also show the relationship between each of these variables.

Factor 1 (Reliability, Service Support, Past Experience, Recommendation, Fuel Consumption and Operator Comfort), Factor 2 (Brand Name, Resale Value) and Factor 3 (Productivity, Less Downtime and Parts network) are found to be statistically significant through multiple regression. The factor 1,2 and 3 have been newly named as Basic requirement of the machine, Brand Image and Productivity \& spare parts availability.

Table 8 Model Summary for Customer purchase decision towards JCB Backhoe Loader Machine

\begin{tabular}{|c|c|c|c|c|}
\hline \multicolumn{5}{|c|}{ Model Summary } \\
\hline Model & R & R Square & Adjusted R Square & Std. Error of the Estimate \\
\hline 1 & 0.574 & 0.329 & 0.327 & 0.28930 \\
\hline 2 & 0.722 & 0.522 & 0.519 & 0.24465 \\
\hline 3 & 0.731 & 0.535 & 0.530 & 0.24174 \\
\hline
\end{tabular}


An Empirical Study on Analyzing Customer Buying Behavior towards JCB Backhoe Loader Machine at Deccan Sales and Services Private Limited, Indore

Table 9 ANOVA for Customer purchase decision towards JCB Backhoe Loader Machine

\begin{tabular}{|c|c|c|c|c|c|c|}
\hline & Model & Sum of & df & Mean Square & $\mathbf{F}$ & Sig. \\
\hline \multirow{3}{*}{1} & Regression & 13.284 & 1 & 13.284 & 158.722 & 0.000 \\
\hline & Residual & 27.034 & 323 & 0.084 & & \\
\hline & Total & 40.318 & 324 & & & \\
\hline \multirow{3}{*}{2} & Regression & 21.046 & 2 & 10.523 & 175.819 & 0.000 \\
\hline & Residual & 19.272 & 322 & 0.060 & & \\
\hline & Total & 40.318 & 324 & & & \\
\hline \multirow{3}{*}{3} & Regression & 21.560 & 3 & 7.187 & 122.976 & 0.000 \\
\hline & Residual & 18.759 & 321 & 0.058 & & \\
\hline & Total & 40.318 & 324 & & & \\
\hline
\end{tabular}

The above tables indicate that null hypothesis can be rejected and thus $\mathrm{Y}$ depends on at least one of the $\mathrm{F}_{\mathrm{i}}$ 's.

\section{Inference about an individual slope $(\beta)$}

Null Hypothesis: $F_{i}$ is not a significant explanatory variable i.e $\mathrm{H}_{0}: \beta_{i}=0$

Alternate Hypothesis: $F_{i}$ is a significant explanatory variable i.e $\mathrm{H}_{1}: \beta_{i} \neq 0$

Table 10 Coefficients for Customer Purchase Decision towards JCB backhoe loader machine

\begin{tabular}{|c|c|c|c|c|c|c|}
\hline \multicolumn{7}{|c|}{ Regression Coefficients } \\
\hline \multicolumn{2}{|r|}{ Model } & \multicolumn{2}{|c|}{ Unstandardized Coefficients } & \multirow{2}{*}{$\begin{array}{c}\begin{array}{c}\text { Standardized } \\
\text { Coefficients }\end{array} \\
\text { Beta } \\
\end{array}$} & \multirow[t]{2}{*}{$\mathbf{t}$} & \multirow[t]{2}{*}{ Sig. } \\
\hline & & B & Std. Error & & & \\
\hline & (Constant) & 4.087 & 0.016 & & 254.703 & 0.000 \\
\hline 1 & $\begin{array}{l}\text { REGR factor score } 2 \text { for } \\
\text { analysis } 1\end{array}$ & 0.202 & 0.016 & 0.574 & 12.598 & 0.000 \\
\hline \multirow{3}{*}{2} & (Constant) & 4.087 & 0.014 & & 301.196 & 0.000 \\
\hline & $\begin{array}{l}\text { REGR factor score } 2 \text { for } \\
\text { analysis } 1\end{array}$ & 0.202 & 0.014 & 0.574 & 14.898 & 0.000 \\
\hline & $\begin{array}{l}\text { REGR factor score } 1 \text { for } \\
\text { analysis } 1\end{array}$ & 0.155 & 0.014 & 0.439 & 11.388 & 0.000 \\
\hline \multirow{4}{*}{3} & (Constant)- alpha & 4.087 & 0.013 & & 304.816 & 0.000 \\
\hline & $\begin{array}{l}\text { REGR factor score } 2 \text { for } \\
\text { analysis } 1-\text { Basic requirement } \\
\text { of the } \\
\text { machine }\end{array}$ & 0.202 & 0.013 & 0.574 & 15.077 & 0.000 \\
\hline & $\begin{array}{l}\text { REGR factor score } 1 \\
\text { for analysis } 1-\text { Brand Image }\end{array}$ & 0.155 & 0.013 & 0.439 & 11.525 & 0.000 \\
\hline & $\begin{array}{l}\text { REGR factor score } 3 \text { for } \\
\text { analysis } 1 \text { - Productivity and } \\
\text { spare } \\
\text { parts availability }\end{array}$ & 0.040 & 0.013 & 0.113 & 2.964 & 0.003 \\
\hline
\end{tabular}

Factor 1 (Reliability, Service Support, Past Experience, Recommendation, Fuel Consumption and Operator Comfort), Factor 2 (Brand Name, Resale Value) and Factor 3 (Productivity, Less Downtime and Parts network) are found to be statistically significant through multiple regression.

The regression equation is found out to be:

$\mathrm{Y}($ Mean Purchase Decision $)=4.087+0.155 \mathrm{~F} 2$ (Brand Image) $+0.202 \mathrm{~F} 1$ (Basic requirement of the machine) $+0.040 \mathrm{~F} 3$ (Productivity \& spare parts availability)

It can be concluded from the above tables that null hypothesis can be rejected and F1, F2 and F3 are significant explanatory variable. 
The coefficient of (multiple) determination $\left(\mathrm{R}^{2}\right)$ is 0.535 and the F-ratio is found to be 122.97, which is significant. Thus, one can conclude that regression model is significant to explain the purchase decision of a JCB Backhoe Loader Machine. The value of $\mathrm{R}^{2}$ should vary between 0 and 1 . This $\mathrm{R}^{2}$ value signifies the proportion of total variation in purchase decision of a JCB Backhoe Loader Machine that is accounted for by the variation in the factors influencing this purchase decision. The strength of association between purchase decision and its influencing factors found out to be average because of the following reasons and recommendations:

- All the variables considered in this study are found to be significant in the regression model. However, the average $\mathrm{R}^{2}$ indicates that the variables considered may be insufficient. Having said that there may be a few more variables that can be explored through further literature review and might contribute to further increase the $\mathrm{R}^{2}$ value.

- The strong brand loyalty and brand impression of JCB Backhoe loader Machine in the minds of the respondents might be a reason for their biased responses. A 7 pointer Likert scale might provide the required precision and variation in the responses.

Table 11 Excluded Variables

\begin{tabular}{|c|c|c|c|c|c|c|}
\hline \multicolumn{7}{|c|}{ Excluded Variables } \\
\hline \multirow{2}{*}{\multicolumn{2}{|c|}{ Model }} & \multirow[t]{2}{*}{ Beta In } & \multirow[t]{2}{*}{$t$} & \multirow[t]{2}{*}{ Sig. } & \multirow{2}{*}{$\begin{array}{c}\text { Partial } \\
\text { Correlation }\end{array}$} & Collinearity \\
\hline & & & & & & nce \\
\hline \multirow{2}{*}{1} & $\begin{array}{l}\text { REGR factor score } 1 \text { for } \\
\text { analysis } 1\end{array}$ & 0.439 & 11.388 & 0.000 & 0.536 & 1.000 \\
\hline & $\begin{array}{l}\text { REGR factor score } 3 \text { for } \\
\text { analysis } 1\end{array}$ & 0.113 & 2.497 & 0.013 & 0.138 & 1.000 \\
\hline 2 & $\begin{array}{l}\text { REGR factor score } 3 \text { for } \\
\text { analysis } 1\end{array}$ & 0.113 & 2.964 & 0.003 & 0.163 & 1.000 \\
\hline
\end{tabular}

The table 11 shows the excluded variables in the stepwise regression for model 1 and model 2 however during the model 3 of stepwise regression, all the variables were included in the regression analysis. Thus, there are no excluded variables in this regression analysis.

\section{CONCLUSIONS AND DISCUSSIONS}

\subsection{Conclusion for objective 1}

The factor extracted in exploratory factor analysis are Basic requirement of the machine, Brand Image and Productivity \& spare parts availability. These are the factors of brand selection of JCB Backhoe Loader Machine. The JCB backhoe loader customer think that a backhoe loader machine can be purchased by considering these factors namely Reliability, Service Support, Past Experience, Recommendation, Fuel Consumption and Operator Comfort as basic requirements of the machine. They also consider Brand Name and Resale Value of the machine as a part of Brand Image. Additionally, they also think that a backhoe loader machine which is supposed to be purchase should have Productivity, Less Downtime and Parts network.

\subsection{Conclusion for objective 2}

It can be concluded that all the three explored factors namely Basic requirement of the machine, Brand Image and Productivity \& spare parts availability are found to be significant in determining the purchase decision of JCB Backhoe Loader Machine. It indicates that the customers of JCB backhoe loader machine primarily consider these three factors as very important while making a purchase decision. 
An Empirical Study on Analyzing Customer Buying Behavior towards JCB Backhoe Loader Machine at Deccan Sales and Services Private Limited, Indore

\subsection{Managerial Implications}

The results have helped to understand the customer purchase decision of JCB backhoe loader machine.

According to the hypothetical market structure JCB is the market Leader since so many years. This study may give an insight to all those brands that come under the category of Market challenger, Market follower and Market Nicher.

This study may help dealer like Deccan Sales \& Services Private Limited to design and implement new strategies with respect Mahindra's Earth-master backhoe loader machine.

\subsection{Limitations}

The results obtained in this study are subject to some limitations as mentioned below:

This is not a comparative study.

Since the responses were recorded on a Likert scale, there were no available means to verify the accuracy of the data collected. Thus, it was assumed that the data was error free.

The ability to generalize the results may be affected by the size and composition of the sample.

The analysis was limited to JCB Backhoe Loader customers of Indore region and select cities of Madhya Pradesh. The other region may result into different conclusion.

.A questionnaire that broadly covers on purchase decision of JCB Backhoe Loader Machine has been used to gather information from the customers who own JCB Backhoe Loader Machine.

The data collected was cross-sectional.

\section{APPENDIX I QUESTIONNAIRE}

On a scale of (1) Strongly disagree (2) Disagree (3) Neither agree nor disagree (4) Agree (5) Strongly agree, please circle (O) the appropriate rating.

1) Seller and location of a store: While planning to make a purchase of a machine, you consider convenience to reach the showroom as an important factor.

2) Price of the product: While making a purchase decision you are convinced even if the price of the machine is worth with regards to its quality.

3) Delivery and Warrantees: While making a purchase decision, you consider a promise or a guarantee given by the company with respect to repair or replacement of a defective machine as important.

4) Credit Arrangements: Since the machine cost is huge and difficult to be paid at once, provision/availability of more number of EMI/credit options and less down-payment becomes very important while making a purchase decision.

5) Maintenance Arrangements: Since the usage rate of the machine is high and requires continuous maintenance, the type of arrangements made by the manufacturer/seller for the same after sales carries a lot of weightage.

6) Brand Name: You do not trust in any backhoe loader machine company other than JCB.

7) Reliability: JCB gives consistent performance from its first usage till the last usage before sending for servicing.

8) Service Support: JCB provides top-notch basic repair service, preventive maintenance, component, Engine and fabrication service.

9) Past Experiences, Resale Value and Productivity: While making a repeat purchase the past experience, resale value and high productivity

Of JCB backhoe loader machine are the important decision making parameters. 


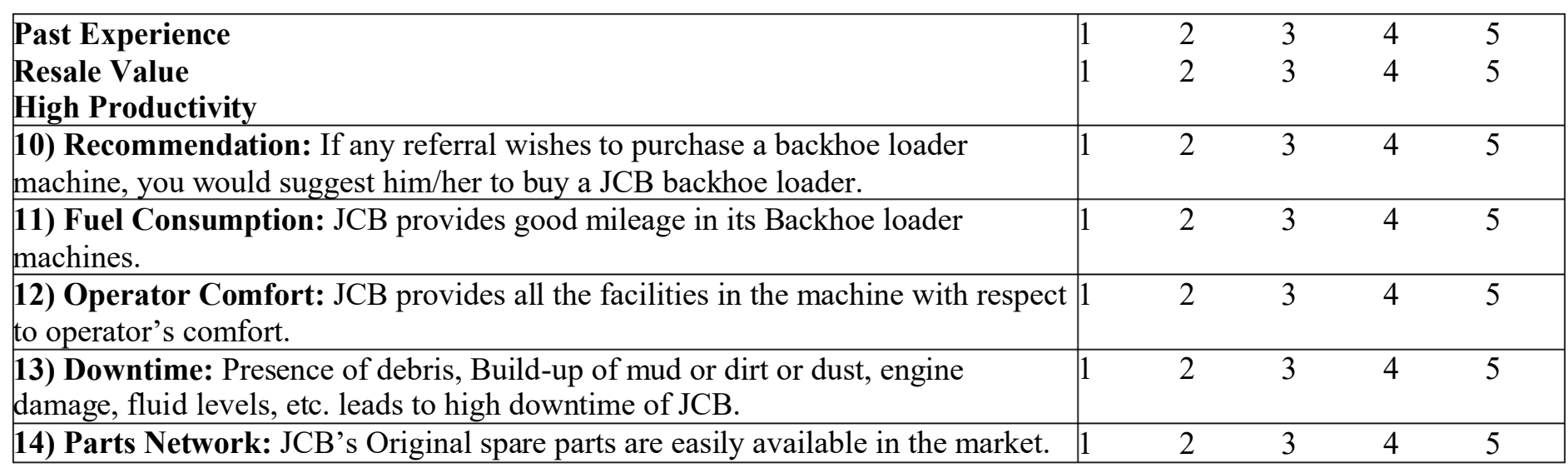

\section{REFERENCES}

[1] Kotler, P. (2015). Marketing Management, $14^{\text {th }}$ ed. Pearson Education India.

[2] Levin, R. \& Rubin, D. (2002). Statistics for Management. Prentice Hall of India Private Limited. India

[3] Malhotra, N. \& Dash, S. (2009). Marketing Research- An Applied Orientation. 5th ed. Pearson Education India

[4] Manikandan, M., Adhiyaman, M \& Pazhani, K.C. (2018). A study and analysis of construction equipment management used in construction projects for improving productivity. International Research Journal of Engineering and Technology, 5(3):1297-1303.

[5] Panchantham, S.K., Natarajan, P., \& Kannan, S. (2014). Dynamics of Industrial Buyer Behavior of Loader Backhoe. Management Studies and Economic Systems, 13(5/6): 371-386.

[6] Sajoudi, M.N., Sadi, M.K., Abdullah, A., Kasraei,M. \& Rezaie, H. (2011). Evaluation of Factors Affecting on Construction Equipment Acquisition Methods in Malaysia. International Conference on Information and Finance IPEDR, 21: 57-61.

[7] Sengat, S. (2019). Quantifying the Factors Influencing Buyer's Purchase Decision in the Light Commercial Vehicle: A Study Conducted In the Pune Region. International Journal of Recent Technology and Engineering, 8(1): 573-579.

[8] Sharma, P., \& Sharma, D. (2017). A conceptual study on Industrial Buying Behavior on heavy commercial vehicle in India. Journal of Emerging Technologies and Innovative Research, 4(12):1217-1224. 